\title{
Vascular training does matter in the outcomes of saphenous high ligation and stripping
}

Ricardo Castro-Ferreira, MD, ${ }^{a, b}$ Maria João Quelhas, MD, ${ }^{a}$ Alberto Freitas, PhD, ${ }^{c}$ José Vidoedo, MD,

Emanuel Alves Silva, MD, ${ }^{e}$ André Marinho, MD, ${ }^{f}$ Rodolfo Abreu, MD, ${ }^{9}$ Andreia Coelho, MD, ${ }^{h}$

Paulo Gonçalves Dias, MD, ${ }^{\mathrm{b}}$ and Sérgio Moreira Sampaio, MD, PhD, , ${ }^{\mathrm{b}}$ Porto, Penafiel, Lisboa, Coimbra, and

Espinho, Portugal

\begin{abstract}
Objective: Varicose vein (VV) surgery is frequently performed by surgeons without formal vascular training. We aimed to compare the outcomes of the procedure based on the background of the surgeon.

Methods: All patients registered with VV surgery between 2004 and 2016 in Portuguese public hospitals were included in the study. Intrahospital outcomes were assessed from this administrative database. A random multicenter sample of 315 patients submitted to saphenous high ligation and stripping (175 patients from six vascular surgery departments and 140 patients from five general surgery divisions) were further queried over the phone, whereby additional nonregistered outcomes were evaluated: preoperative venous ultrasound, impact on quality of life by the 14-item Chronic Venous Insufficiency Quality of Life Questionnaire, visual analogue scale evaluation (score of 1 to 5) of the aesthetic results and general satisfaction, work absence days, and time to return to physical activities.
\end{abstract}

Results: In 13 years, there were 153,382 patients submitted to WV surgery. Of these, 49\% were operated on by general surgeons and $40 \%$ by vascular surgeons; in $11 \%$, it was not possible to identify the specialty performing the operation. Twenty-three deaths were registered (no differences between groups). In the general surgery group, $14 \%$ of patients were hospitalized for more than one night compared with 3\% in the vascular group $(P<.001)$. Reintervention rate during the period analyzed was significantly higher in the general surgery group (13.5\% vs $8.2 \% ; P<.001)$. Rate of outpatient surgery was higher in the vascular surgery group (60\% vs 36\%; $P<.001)$. Phone query revealed similar overall satisfaction and improvement in quality of life in both groups (4.2 vs $4.0[P=.275]$ and $35 \%$ vs $36 \%[P=.745]$, respectively). However patients operated on by general surgeons reported worse surgical scars (2.8 vs 2.1; $P=.007$ ), higher number of residual VVs (2.4 vs 1.7; $P=.006$ ), and higher number of days absent from work ( 40 vs 27 days; $P=.005$ ) and took longer to resume physical activities (60 vs 41 days; $P=.001$ ).

Conclusions: Despite that the majority of $\mathrm{W}$ surgery in Portugal is executed by general surgeons, this study highlights important advantages when it is performed by surgeons with vascular training. (J Vasc Surg: Venous and Lym Dis 2019;7:732-8.)

Keywords: Varicose veins; Vascular surgery; Patient-reported outcome measures; Cosmetic techniques; Quality of life

Varicose veins (Ws) affect approximately one-third of the adult population, with reported prevalence in the range of $25 \%$ to $40 \%$ in women and $10 \%$ to $40 \%$ in men. . $^{1-6}$ The negative impact on quality of life has been well described in multiple studies. ${ }^{7,8} \mathrm{~V}$ s result in physical limitations and impaired mental quality of life, 9,10 whereas complications of V $\mathrm{V}$ also contribute to substantial costs of treatment and are a burden to the health care system. ${ }^{17-13}$ Chronic venous diseases, in particular VVs and their complications, are responsible for significant absenteeism and premature retirement. ${ }^{14,15}$ Despite recent minimally

From the Departamento de Cirurgia e Fisiologia, Unidade de Investigação Car diovascular, ${ }^{a}$ and Centro de Investigação e Tecnologia de Informação em Sis temas de Saúde (CINTESIS) e Departamento de Ciências da Informação e da Decisão em Saúde, ${ }^{c}$ Faculdade de Medicina da Universidade do Porto, and the Serviço de Angiologia e Cirurgia Vascular, Centro Hospitalar São João, Porto; the Serviço de Angiologia e Cirurgia Vascular. Centro Hospitalar Tãmega e Sousa, Penafield; the Serviço de Angiologia e Cirurgia Vascular, Centro Hospitalar Lisboa Norte, ${ }^{e}$ and Serviço de Angiologia e Cirurgia VascuIar, ${ }^{9}$ Centro Hospitalar Lisboa Central, Lisboa; the Serviço de Angiologia e Cirurgia Vascular, Centro Hospitalar e Universitário de Coimbra, Coimbraf; and the Serviço de Angiologia e Cirurgia Vascular, Centro Hospitalar de Vila Nova de Gaia e Espinho, Espinho. ${ }^{\text {h }}$ invasive techniques, classic VV surgery continues to have an important role in the management of varices, being the most frequent vascular procedure in Europe. ${ }^{16,17}$ As the socioeconomic impact grows, it becomes essential to measure outcomes and patients' satisfaction with this surgery in the public health care system. Vein surgery in Portugal, as in several other countries, has the particularity of being performed by surgeons with and without vascular training. Interestingly, published results from Spain highlight that the majority of patients in public national health hospitals are treated by general surgeons. ${ }^{18}$ In Portugal,

Author conflict of interest: none.

Correspondence: Ricardo Castro-Ferreira, MD, Departamento de Cirurgia e Fisiologia, Faculdade de Medicina da Universidade do Porto, Alameda Prof. Hernâni Monteiro, 4200-319 Porto, Portugal (e-mail: cferreira.ricardo@gmail. com).

The editors and reviewers of this article have no relevant financial relationships to disclose per the Journal policy that requires reviewers to decline review of any manuscript for which they may have a conflict of interest.

2213-333X

Copyright (c) 2019 by the Society for Vascular Surgery. Published by Elsevier Inc. https://doi.org/10.1016/j.jvsv.2019.01.060 
general surgery and vascular surgery are independent specialties with distinct pathways of differentiation. During 6 years of training, general surgeons have only an optional 3 months dedicated to vascular surgery. The aim of this article was to evaluate the impact of vascular training on the outcomes of saphenous high ligation and stripping.

\section{METHODS}

This was a retrospective multicenter cohort study. Every patient registered with the International Classification of Diseases, Ninth Revision procedure code 3859 (ligation and stripping of VVs, lower limb veins) in Portuguese public hospitals between January 2004 and December 2016 was included in the study. This is the standard code used for $\mathrm{V}$ surgery in all public hospitals. The information was obtained from the national administrative database of health care, a mandatary administrative registry for hospital refunding. The obtained cohort was separated into three groups with respect to the vascular training of the surgeon performing the procedurevascular surgery, general surgery, and undefined. A procedure was classified as general surgery when it was performed in hospitals with no vascular surgeons. If the hospital has both vascular and general surgeons performing $\mathrm{V} V$ surgery, the procedure was labeled undefined. The outcomes assessed were mortality, hospitalization for more than one night, need of blood transfusion, and reintervention rate. Frequency of outpatient surgery was also evaluated. These primary outcomes were compared between patients operated on by surgeons with and without a vascular background.

A random multicenter sample was further studied by phone query. The minimum sample number for a confidence interval of $95 \%$ and $10 \%$ accepted margin of error for a response distribution of 50\% was calculated using dedicated software (www.raosoft.com)-96 individuals. To limit memory bias, only patients operated on in the 6 months before the phone assessment were included. The six centers with highest volume of $\mathrm{VV}$ surgery of both vascular surgery and general surgery in Portugal were invited to provide patients' data from the first five operations fulfilling the inclusion criteria each month during the evaluated 6 months (30 patients per center). The inclusion criteria were age between 18 and 60 years and at least one saphenous vein removed by classic surgery technique (high ligation and stripping). Exclusion criteria were prior history of $\mathrm{V} V$ surgery, surgery by endovenous technique, and inability to answer an oral questionnaire. Phone query was conducted by an independent physician. In this sample, 11 outcomes were analyzed: classification of chronic venous insufficiency before surgery (Clinical, Etiology, Anatomy, and Pathophysiology classification); preoperative venous ultrasound; surgical technique (short vs long stripping and bilateral vs unilateral, crosschecked with surgical report); impact of surgery on quality of life by the

\section{ARTICLE HIGHLIGHTS}

Type of Research: Retrospective multicenter cohort study

Key Findings: Evaluation of 153,382 varicose vein procedures performed in Portugal during a period of 13 years and further assessment of 315 patients revealed that patients operated on by vascular surgeons had similar overall satisfaction and improvement in quality of life but lower reintervention rates, shorter hospitalization time, fewer residual varices, and better surgical scars and were absent from work for fewer days

- Take Home Message: The authors suggest that despite being frequently executed by surgeons without vascular background, varicose vein surgery has significant advantages when it is performed by vascular surgeons.

14-item Chronic Venous Insufficiency Quality of Life Questionnaire (CIVIQ-14); aesthetic results after surgery by visual analogue scale (VAS): presence of residual varices (score of 1 to 5 , where 1 is nonexistent and 5 is several) and aspect of scars (evaluated from 1 to 5 , where 1 is imperceptible and 5 is deforming); impact on postoperative period: pain during first week (VAS score of 1 to 5), days off work, and days to return to physical activities; general satisfaction (VAS score of 1 to 5); and whether the patient would repeat the surgery in the future. Contacted patients provided verbal informed consent for the questionnaire and publication of the results. The project was approved by the local ethics committee and was conducted in accordance with the principles outlined in the Declaration of Helsinki.

Data were treated by SPSS Statistics software (version 21.0.0; IBM Corp, Armonk, NY). Categorical outcomes were compared using $\chi^{2}$ test. Mann-Whitney test was used to compare noncategorical outcomes. $P$ values $<.05$ were considered to represent a significant difference.

\section{RESULTS}

Between 2004 and 2016, there were 153,382 patients registered with ligation and stripping of $V V s$ in the national administrative database. The mean age of the group was 49.7 years, and $76 \%$ were female; $49 \%$ of the patients were operated on by general surgeons and $40 \%$ by vascular surgeons (75,274 vs 60,925 patients). In $11 \%$ of the patients, it was not possible to identify the specialty that performed the operation as it was performed at hospitals where both specialties do WV surgery. Yearly assessment shows that the number of VV operations performed in public hospitals steadily increased in the observed time and that from 2012, vascular surgery overcame general surgery in the number of procedures (Fig 1). The outcomes evaluated in this cohort are 


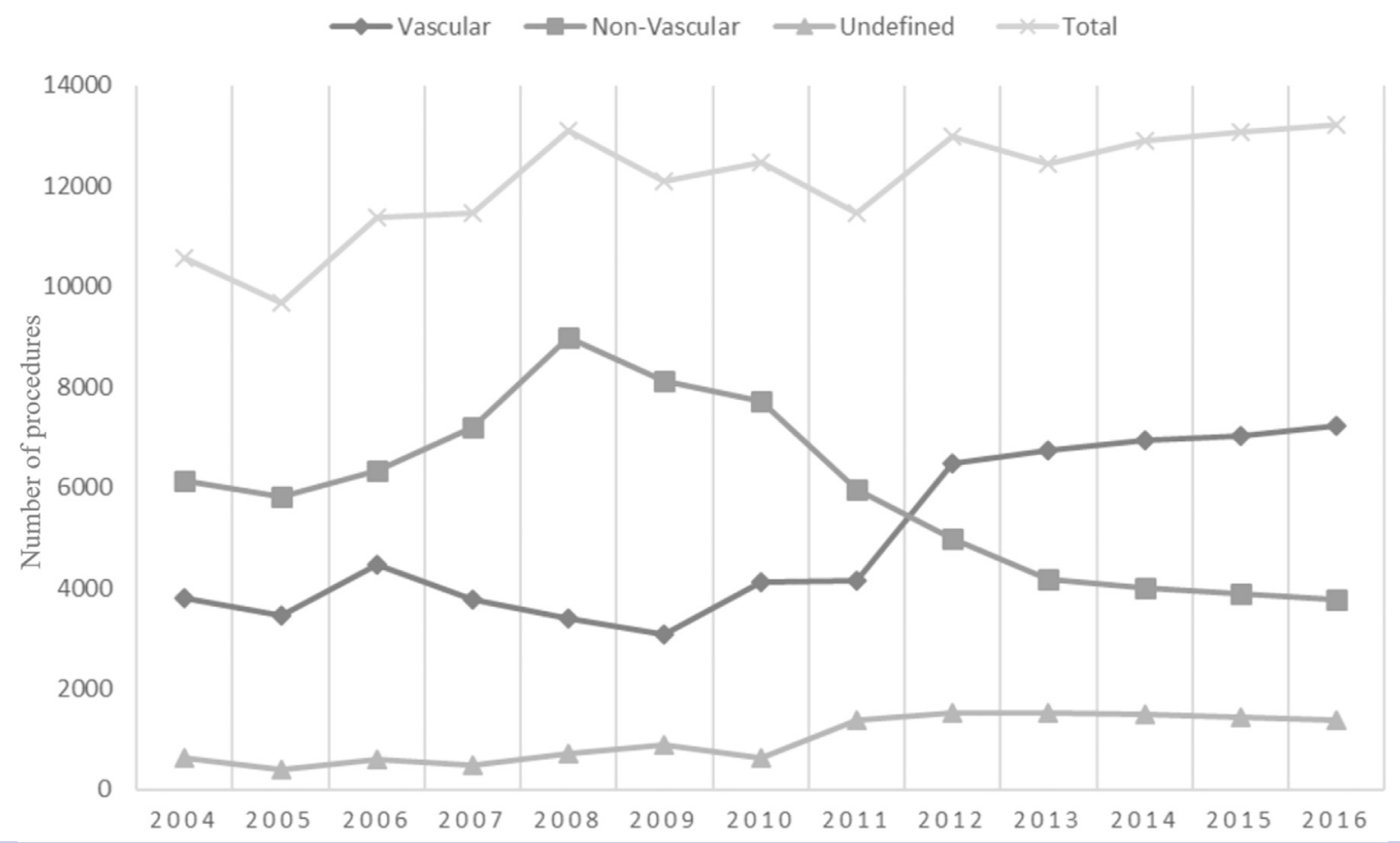

Fig 1. Yearly assessment of the number of varicose vein (VV) operations performed in public hospitals segregated by vascular training.

detailed in Table I, and the baseline characteristics of the groups are summarized in Table II.

During the evaluated time, 23 intrahospital deaths were registered: 10 in the general surgery group, 9 in the vascular surgery group, and 4 in the undefined group (no difference between groups). In the same hospital stay, 179 patients needed blood transfusion, with no significant differences between the three groups. In the subgroup of patients operated on by surgeons without vascular training, $14 \%$ of patients were hospitalized for more than one night compared with 3\% in the vascular surgery group $(P<.001)$. Rate of outpatient surgery was also different, being higher in the vascular surgery group, in which $60 \%$ patients were operated on as outpatients compared with just $36 \%$ in the general surgery group $(P<.001)$. The rate of outpatient surgery significantly increased in both groups, constituting, in 2016, $88 \%$ of the procedures performed by vascular surgeons and $70 \%$ by general surgeons (Fig 2). Reintervention rate during the period analyzed was significantly higher in the general surgery group $(13.5 \%$ vs $8.2 \%$; $P<.001)$.

A total of 315 patients were successfully evaluated by phone; this included 175 patients from six vascular surgery departments and 140 patients from five general surgery divisions (one general surgery department refused to provide data). Because of patients' not answering the phone or a wrong number provided, it was not possible to contact 15 patients (5 from vascular surgery and 10 from general surgery). Patients' baseline characteristics are detailed in Table II, and the results from the phone query are summarized in Table III. There was a significant increase in the quality of life assessed by the CIVIQ-14 in both groups (Fig 3). This improvement was similar in both clusters (35\% vs $36 \%$ in the nonvascular group; $P=.745$ ), as was the overall satisfaction of the patient (VAS score of 4.2 vs 4.0 in the nonvascular group; $P=.275$ ). The majority of the cohort had a venous duplex ultrasound scan before surgery, but only a subset of $15 \%$ in the vascular group had the ultrasound examination performed during surgery. This small sample of patients (with intraoperative duplex ultrasound scan) reported fewer residual varices (VAS score of 1.3 vs 2.8; $P<.001$ ) and greater overall satisfaction (VAS score of 4.4 vs 3.9; $P=.031$ ) than the remaining patients. There was a higher number of patients submitted to short stripping of the great saphenous vein (stripping to below the knee vs stripping to the ankle) in the vascular surgery cohort ( $57 \%$ vs $15 \%$; $P<.001$ ). Short stripping was associated with less postoperative pain ( 2.2 vs 3.0; $P<.001$ ) and fewer days to resume physical activity (38 vs 62 days; $P<.001$ ). A greater number of patients operated on by vascular surgeons had both limbs intervened on in the same surgical time $(72 \%$ vs $35 \% ; P<.001)$. No difference in outcomes was observed with bilateral vs unilateral surgery. Patients operated on by surgeons without vascular training reported worse surgical scars (VAS score of 2.8 vs 2.1; $P=.007$ ), higher number of residual VVs (VAS score of 2.4 vs 1.7; $P=.006$ ), and higher number of days absent from work (40 vs 27 days; $P=.005$ ) and took longer to resume physical activities (60 vs 41 days; $P=.001$ ). A 
Table I. Outcomes evaluated in the national cohort of patients

\begin{tabular}{|c|c|c|c|}
\hline & Vascular surgery $(n=60,925)$ & Nonvascular $(n=75,274)$ & Undefined $(n=17,183)$ \\
\hline Blood transfusion & 52 & $94(P=.08)^{a}$ & 33 \\
\hline Reintervention & $8.2 \%$ & $13.5 \%(P<.001)^{a}$ & 9.1 \\
\hline Outpatient surgery & $59.6 \%$ & $35.9 \%(P<.001)^{a}$ & 44.6 \\
\hline
\end{tabular}

greater proportion of patients operated on by surgeons with vascular training would again agree to be operated on in the future (90\% vs $78 \% ; P=.012)$.

\section{DISCUSSION}

In the last decade, there was a shift in the vascular discussion about $\mathrm{V}$ surgery, with the focus now on assessing endovenous techniques. ${ }^{19,20}$ With that, one tends to forget that classic surgery remains the most frequent treatment modality in several countries, such as Spain ${ }^{18}$ and Germany. ${ }^{21}$ Furthermore, the better outcomes and cost-effectiveness of the endovenous techniques remain debatable. ${ }^{20,22}$ In that regard, assessing high ligation and stripping outcomes in the real world remains an important subject and should not be overlooked. In addition, being the only technique performed by general surgeons in Portugal, it is the only comparable method between surgical groups.

We observed a significant increase in the number operations performed. This cannot be explained by demographics, as the Portuguese population remained stable (2004, 10.47 million; 2016, 10.34 million) and national public hospitals have universal coverage, but arguably by an increased awareness of the disease by patients and physicians. Because of its frequency, chronic venous disease is associated with significant socioeconomic burden; the estimated annual cost of chronic venous disease in western Europe ranges from
$€ 600$ million to $€ 800$ million, representing $1 \%$ to $2 \%$ of the total health care budget. ${ }^{14,23}$ Therefore, a reduction of direct cost related to $\mathrm{V} V$ surgery can have a significant economic impact, which emphasizes the importance of giving the most cost-effective treatment to these patients. In our assessment of 153,000 patients submitted to the procedure, we found a significant increase in the hospitalization time of patients operated on by surgeons without a vascular background as well as a significantly lower number of outpatient operations and a higher number of reinterventions. Moreover, in the smaller cohort of patients analyzed with greater detail, the number of days absent from work was meaningfully larger in the general surgery subgroup. Indeed, it was a mean 13 days faster for a patient operated on by a trained vascular surgeon to resume work. If we multiply by the 75,274 patients operated on by nonvascular surgeons during the assessed time, it is $>978,000$ days of work absence that could be gained had the patient been operated on by a vascular surgeon. All these factors combined point to a significant socioeconomic advantage of this operation's being performed by vascular surgeons.

There was a significant increase in the percentage of operations performed on an outpatient basis in the evaluated time, from $10 \%$ in 2004 to $82 \%$ in 2016 . This increase was higher than that observed in other frequent procedures during the same period in Portugal; cholecystectomy increased from $1 \%$ to $13 \%$ (from a total of

Table II. Patients' demographics and baseline characteristics

\begin{tabular}{|c|c|c|c|c|c|}
\hline & \multicolumn{2}{|c|}{ National cohort } & \multicolumn{2}{|c|}{ Phone query } & $P$ value \\
\hline Female sex & 75.9 & 75.3 & 76.1 & 75.1 & .182 \\
\hline Smoking & 2.8 & 2.5 & 4.9 & 4.7 & .384 \\
\hline $\begin{array}{l}\text { No. of procedures } \\
\text { yearly per center }\end{array}$ & $72.4 \pm 71.1$ & $341 \pm 231.7$ & $277 \pm 78$ & $661 \pm 194$ & $<.001$ \\
\hline CEAP class & NA & NA & $2.6 \pm 0.88$ & $2.7 \pm 0.92$ & .985 \\
\hline
\end{tabular}




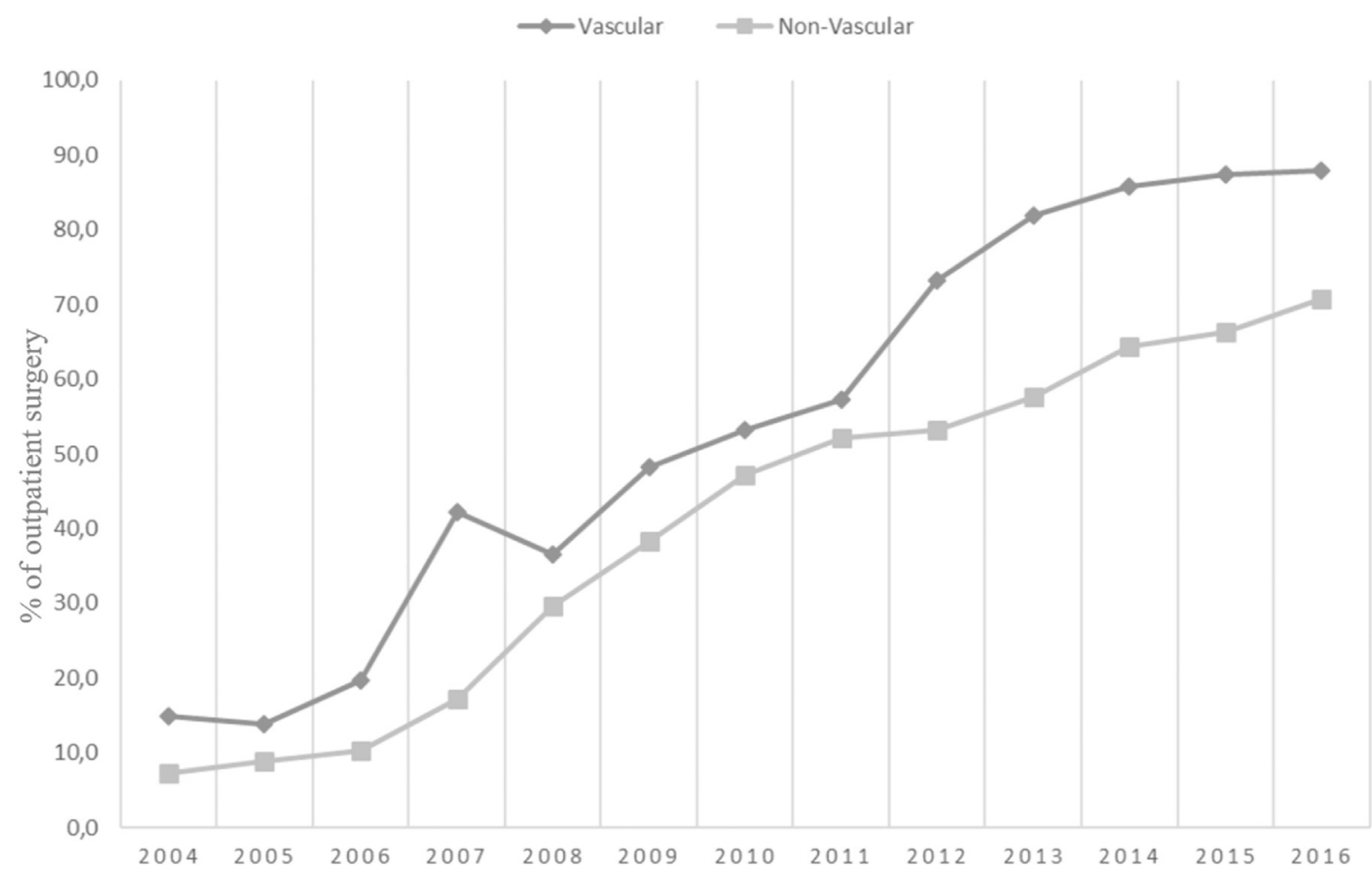

Fig 2. Yearly assessment of the percentage of outpatient surgery performed in public hospitals by vascular and nonvascular surgeons.

212,393 operations), and hernia repairs increased from $14 \%$ to $53 \%$ (from a total of 359,279 procedures; unpublished data extracted from the national administrative database of health care).
Our assessment of the national data from 2004 to 2016 showed no difference in major complications between groups. The further analysis of a random cohort demonstrated that both groups benefited significantly with $\mathrm{V}$

Table III. Baseline characteristics and results from the phone query

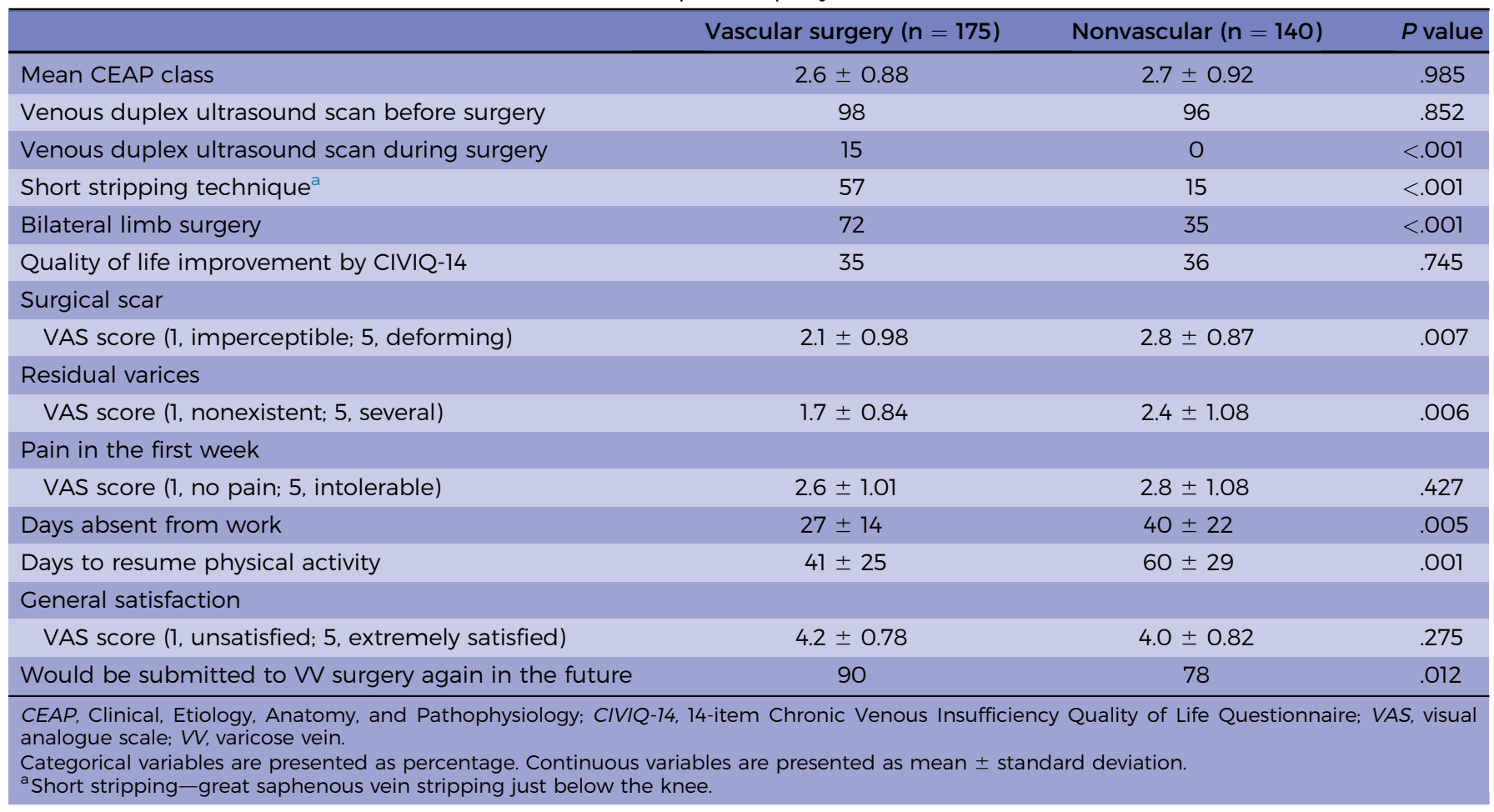




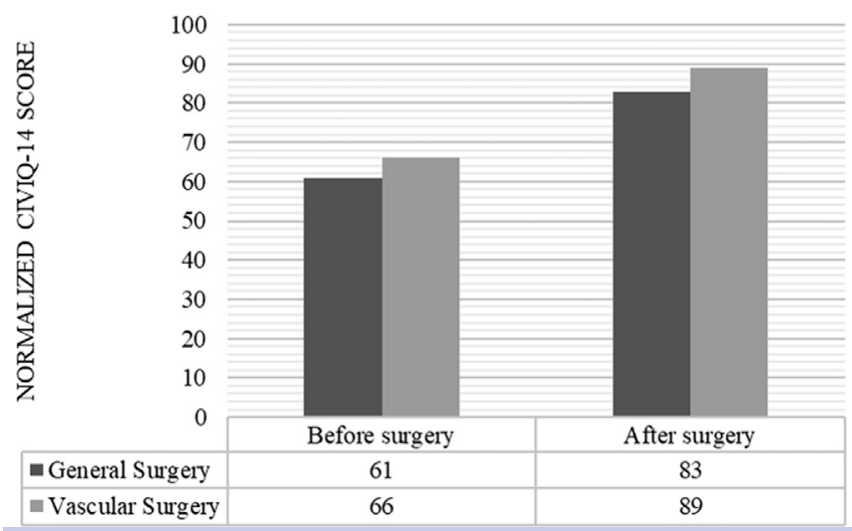

Fig 3. Evaluation of quality of life before and after surgery using the 14-item Chronic Venous Insufficiency Quality of Life Questionnaire (CIVIQ-14).

surgery by showing a similar and significant improvement on CIVIQ-14 score and a great overall satisfaction after surgery. CIVIQ-14 is a simplified and validated form $^{24}$ of the 20 -item CIVIQ, ${ }^{25,26}$ one of the most used questionnaires for quality of life assessment specifically related to this disease. As the inclusion criteria for the random sample included at least one saphenous vein extraction, and the majority of patients in both groups had a duplex ultrasound scan performed before the operation, it is possible to conjecture that the bulk of both groups successfully treated a documented insufficient vein. That can explain the similar improvement in quality of life observed in both groups, which led to the comparable overall satisfaction.

The cosmetic impact of VVs on self-esteem is well known, and it is one of the main reasons that patients seek treatment. ${ }^{27}$ Therefore, the aesthetic result of the surgery should not be overlooked. In this regard, patients operated on by vascular surgeons had fewer residual varices and less perceptive scars. That fact can at least in part explain why patients operated on by surgeons without a vascular background had less tendency to agree to repeat the procedure in the future. This is an important aspect as VV surgery is considered a noncurative procedure, so many patients may need future intervention. $^{28}$

Duplex ultrasound is the imaging modality of choice for the assessment of deep and superficial veins. ${ }^{29}$ The clinical guidelines recommend its use to confirm the diagnosis of VVs and the extent of truncal reflux as well as to plan treatment for patients with primary or recurrent $\mathrm{VVs}{ }^{30,31}$ This recommendation was accomplished by most patients before surgery, but a subset of patients operated on by vascular surgeons had ultrasound examination performed for vein mapping during surgery. This subgroup had greater overall satisfaction, with the best aesthetic results and fewer residual varices. Despite being customary during endovenous techniques, ${ }^{32,33}$ duplex ultrasound scanning during classic $\mathrm{V}$ surgery is seldom described in the literature. Our results suggest that it can have a role in improving the outcomes of the procedure.

Great saphenous vein removal in classic surgery is routinely performed by stripping from the saphenofemoral junction. Because of a greater nerve injury risk most vascular surgeons strip just below the knee (short stripping), avoiding stripping of the great saphenous vein in the calf, where the relation with the saphenous nerve is more intimate. ${ }^{34}$ In fact, according to Holme et al, ${ }^{35}$ stripping to the ankle does not improve symptomatic relief but significantly increases the risk of saphenous nerve injury. In our study, short stripping was found to be practiced more frequently by vascular surgeons and was associated with less postoperative pain and fewer days to resume physical activity. Most surgeons without vascular training in our cohort are still performing the relatively outdated long stripping to the ankle.

Several reasons might contribute to the different outcomes reported by this study. One might question whether general surgeons are operating on higher risk patients or patients with worse VVs. However, our data show strikingly similar groups in regard to both demographics and comorbidities and the Clinical, Etiology, Anatomy, and Pathophysiology venous score (Table II). A major factor that differentiates the groups is the yearly number of procedures each department is performing. In this regard, the significantly higher number of procedures each vascular surgeon is executing can potentially justify the better results observed in this group.

\section{CONCLUSIONS}

To the best of our knowledge, this is the first large study comparing the outcomes of classic $\mathrm{V}$ surgery performed by surgeons with or without vascular training. This study highlights an important improvement in the quality of life and a great overall satisfaction regardless of the surgeon performing the procedure. However, the aesthetic component as well as the socioeconomic burden of this surgery can be improved if the patient is operated on by surgeons with a vascular surgery background. Should this be enough to promote change?

The authors would like to thank the Healthcare Central Administration (Administração Central de Serviços de Saúde) for providing access to the data analyzed in this manuscript. The authors acknowledge the contribution to data collection by José Pinto, Dalila Rolim, Ana Alves, Pedro Febra, and Tobias Teles.

\section{AUTHOR CONTRIBUTIONS}

Conception and design: RCF, MQ, AF, PD, SMS

Analysis and interpretation: RCF, MQ, AF, PD, SMS

Data collection: RCF, MQ, JV, ES, AM, RA, AC

Writing the article: RCF, MQ 
Critical revision of the article: RCF, MQ, AF, JV, ES, AM, RA, AC, PD, SMS

Final approval of the article: RCF, MQ, AF, JV, ES, AM, RA, AC, PD, SMS

Statistical analysis: RCF, MQ, AF

Obtained funding: Not applicable

Overall responsibility: SMS

$\mathrm{RCF}$ and MQ contributed equally to this article and share co-first authorship.

\section{REFERENCES}

1. Evans CJ, Fowkes FG, Ruckley CV, Lee AJ. Prevalence of varicose veins and chronic venous insufficiency in men and women in the general population: Edinburgh Vein Study. J Epidemiol Community Health 1999;53:149-53.

2. Carpentier PH, Maricq HR, Biro C, Poncot-Makinen CO, Franco A. Prevalence, risk factors, and clinical patterns of chronic venous disorders of lower limbs: a population-based study in France. J Vasc Surg 2004;40:650-9.

3. Chiesa R, Marone EM, Limoni C, Volonte M, Schaefer E, Petrini O. Chronic venous insufficiency in Italy: the 24-cities cohort study. Eur J Vasc Endovasc Surg 2005;30:422-9.

4. Criqui $\mathrm{MH}$, Jamosmos $\mathrm{M}$, Fronek $\mathrm{A}$, Denenberg JO, Langer RD, Bergan J, et al. Chronic venous disease in an ethnically diverse population: the San Diego Population Study. Am J Epidemiol 2003;158:448-56.

5. Callam MJ. Epidemiology of varicose veins. Br J Surg 1994;81: 167-73.

6. Beebe-Dimmer JL, Pfeifer JR, Engle JS, Schottenfeld D. The epidemiology of chronic venous insufficiency and varicose veins. Ann Epidemiol 2005;15:175-84.

7. Kaplan RM, Criqui MH, Denenberg JO, Bergan J, Fronek A. Quality of life in patients with chronic venous disease: San Diego population study. J Vasc Surg 2003;37:1047-53.

8. Kelleher D, Lane TR, Franklin IJ, Davies AH. Treatment options, clinical outcome (quality of life) and cost benefit (quality-adjusted life year) in varicose vein treatment. Phlebology 2012;27(Suppl 1):16-22.

9. Kurz X, Lamping DL, Kahn SR, Baccaglini U, Zuccarelli F, Spreafico G, et al. Do varicose veins affect quality of life? Results of an international population-based study. J Vasc Surg 2001:34:641-8.

10. Sritharan K, Lane TR, Davies AH. The burden of depression in patients with symptomatic varicose veins. Eur J Vasc Endovasc Surg 2012;43:480-4.

11. Bergan JJ, Schmid-Schonbein CW, Smith PD, Nicolaides AN, Boisseau MR, Eklof B. Chronic venous disease. N Engl J Med 2006:355:488-98.

12. Piazza G. Varicose veins. Circulation 2014;130:582-7.

13. Lattimer CR. CVD: a condition of underestimated severity. Int Angiol 2014:33:222-8.

14. Rabe E, Pannier F. Societal costs of chronic venous disease in CEAP C4, C5, C6 disease. Phlebology 2010;25(Suppl 1): 64-7.

15. Da Silva A, Navarro MF, Batalheiro J. [The importance of chronic venous insufficiency. Various preliminary data on its medico-social consequences]. Phlebologie 1992:45:439-43.

16. Coughlin PA, Berridge DC. Is there a continuing role for traditional surgery? Phlebology 2015;30(Suppl):29-35.

17. Meissner $\mathrm{MH}$. What is the medical rationale for the treatment of varicose veins? Phlebology 2012;27(Suppl 1):27-33.

18. Morales-Cuenca G, Moreno-Egea A, Aguayo-Albasini JL. [General surgeons and varicose vein surgery]. Cir Esp 2009;85:205-13.
19. Healy DA, Kimura S, Power D, Elhaj A, Abdeldaim Y, Cross KS, et al. A systematic review and meta-analysis of thrombotic events following endovenous thermal ablation of the great saphenous vein. Eur J Vasc Endovasc Surg 2018;56: 410-24.

20. Kheirelseid EA, Crowe G, Sehgal R, Liakopoulos D, Bela H, Mulkern E, et al. Systematic review and meta-analysis of randomized controlled trials evaluating long-term outcomes of endovenous management of lower extremity varicose veins. J Vasc Surg Venous Lymphat Disord 2018;6: 256-70.

21. Kuhlmann A, Prenzler A, Hacker J, Graf von der Schulenburg JM. Impact of radiofrequency ablation for patients with varicose veins on the budget of the German statutory health insurance system. Health Econ Rev 2013:3:9.

22. Carroll C, Hummel S, Leaviss J, Ren S, Stevens JW, Cantrell A, et al. Systematic review, network meta-analysis and exploratory cost-effectiveness model of randomized trials of minimally invasive techniques versus surgery for varicose veins. Br J Surg 2014:101:1040-52.

23. Jantet $\mathrm{C}$. [The socioeconomic impact of venous pathology in Great Britain]. Phlebologie 1992;45:433-7.

24. Launois R, Le Moine JG, Lozano FS, Mansilha A. Construction and international validation of CIVIQ-14 (a short form of CIVIQ-20), a new questionnaire with a stable factorial structure. Qual Life Res 2012;21:1051-8.

25. Launois R, Mansilha A, Lozano F. Linguistic validation of the 20 item-chronic venous disease quality-of-life questionnaire (CIVIQ-20). Phlebology 2014:29:484-7.

26. Launois R, Mansilha A, Jantet G. International psychometric validation of the Chronic Venous Disease quality of life Questionnaire (CIVIQ-20). Eur J Vasc Endovasc Surg 2010;40: 783-9.

27. O'Leary DP, Chester JF, Jones SM. Management of varicose veins according to reason for presentation. Ann R Coll Surg Engl 1996;78(Pt 1):214-6.

28. van Rij AM, Jiang P, Solomon C, Christie RA, Hill GB. Recurrence after varicose vein surgery: a prospective long-term clinical study with duplex ultrasound scanning and air plethysmography. J Vasc Surg 2003:38:935-43.

29. Spinedi L, Broz P, Engelberger RP, Staub D, Uthoff $H$. Clinical and duplex ultrasound evaluation of lower extremities varicose veins-a practical guideline. Vasa 2017:46:325-36.

30. Marsden G, Perry M, Kelley K, Davies AH; Guideline Development Group. Diagnosis and management of varicose veins in the legs: summary of NICE guidance. BMJ 2013;347: f4279.

31. Gloviczki P, Comerota AJ, Dalsing MC, Eklof BG, Gillespie DL, Gloviczki ML, et al. The care of patients with varicose veins and associated chronic venous diseases: clinical practice guidelines of the Society for Vascular Surgery and the American Venous Forum. J Vasc Surg 2011;53(Suppl):2S-48S.

32. Mowatt-Larssen E. Management of secondary varicosities. Semin Vasc Surg 2010;23:107-12.

33. Johnson CM, McLafferty RB. Endovenous laser ablation of varicose veins: review of current technologies and clinical outcome. Vascular 2007;15:250-4.

34. van den Bremer J, Moll FL. Historical overview of varicose vein surgery. Ann Vasc Surg 2010;24:426-32.

35. Holme JB, Skajaa K, Holme K. Incidence of lesions of the saphenous nerve after partial or complete stripping of the long saphenous vein. Acta Chir Scand 1990;156:145-8. 